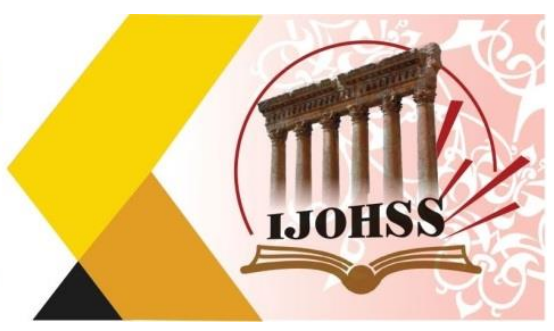

\title{
أثر استخدام إستراتيجية الأنشطة المتدرجة في التفكير المستقبلي لاى طالبات الصف الثاني متوسط في مادة العلوم التئه
}

$$
\text { أ.د. هادية كطفان شون }
$$

م.م. مولاءع داخل كُطفان

المديرية العامة لتربية القادية دطية

الملخص

يهدف البحث الحالي التعرف على اثر استخدام إستراتيجية الانشطة المندرجة في التفكير المستقبلي لدى طالبات الصف الثاني المتوسط في مادة العلوم ، وقد استعان الباحثون بالتصميم التجريبي عشوائي الاختيار ذي الاختبار البعدي و الضبط الجزئي لمجمو عتين متكافيتتين ( تجريبية و ضابطة ) حيث تكونت عينة البحث من ( 70 ) طالبة من طالبات الصف الثاني منوسط في منوسطة الجمهوريـة للبنـات التابعة الى المديريـة العامـة لتربيـة الديو انيـة ،

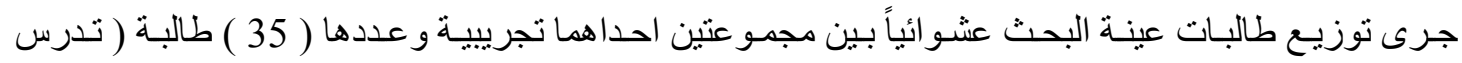
بإستر اتيجية الانشطة المتدرجة ) و الاخرى ضـابطة عددها ( 35 ) طالبـة ( تدرس بالطريقة التقلبديـة ) ، كوفئت

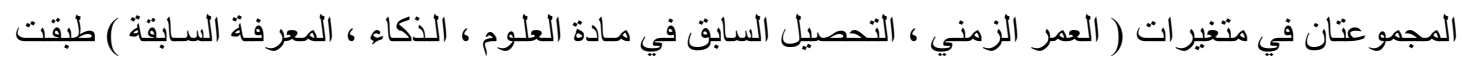
التجربة في الفصل الاول للعام الدر اسي ( 2019 - 2020 ) ودرست مجموعني البحث ، اعد الباحثين اختباراً لمهار ات التفكير المستقبلي و المكون من ( 24 ) فقرة من نوع الاختبار المقالي موزعة الى سته مهار ات لكل مهارة اربع فقرات ـ استعمل البـاحثين عدد من الوسـائل الاحصـائية منها ، الاختيـار التائي ( T.test) لعينتين

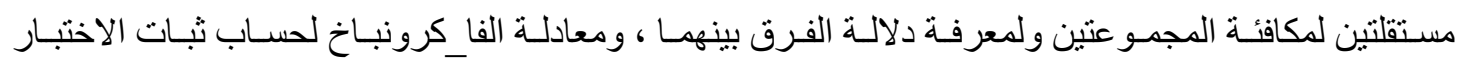
التحصيلي ، ومعامل الصعوبة ، ومعامل تمييز الفقرات ، اظهرت النتائج الخاصـة بالبحث على تفوق الطالبات

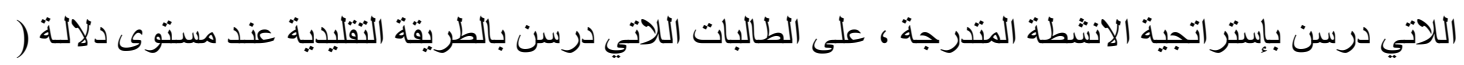

الكلمات المفتاحية: إستر اتيجية الأنشطة المتدرجة، التفكير المستقبلي، الصف الثاني متوسط، مادة العلوم. 


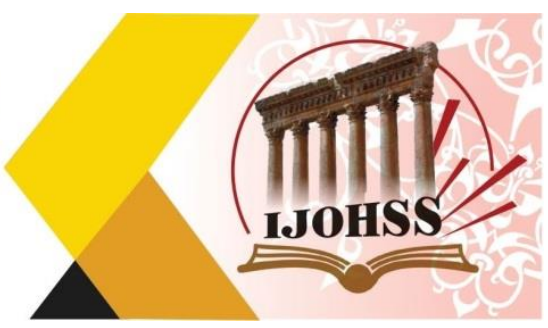

\title{
The Effect of Using The Strategy of Graduated Activities on Future Thinking among Second- Grade Intermediate Students in The Science Subject
}

\author{
Walaa Inside Kattfan
}

Prof.Dr. Hady Katfan Shoun

\begin{abstract}
The present research, aims to identify the effect of using the strategy of gradual activities in the future thinking of second grade students in the subject of science, the researchers used a randomized experimental design with post-test and partial control of two equivalent groups (experimental and control). The research sample consisted of (70) pupils second grade students in the middle of Al-jumhuriaa for girls affiliated to the Directorate General of the Education Diwaniyah. The students of the research sample were randomly distributed between two groups, one of them is experimental and there are (35) students studying the strategy of gradual activities.

The other officer (35) students studying in the traditional way. The two groups were rewarded in variables (chronological age, previous achievement in science, intelligence, Previous knowledge). Experience was applied in the first semester of the academic year (2019-2020), the two groups studied by one of the researchers, the researchers prepared a test of future thinking skills consisting of (24) paragraphs of the essay test type distributed over six skills for each skill four paragraphs. The researchers used a number of statistical methods, including (T-test) for two independent samples to reward the two groups and to know the significance of the difference between them, Alpha-kronbach equation to calculate the stability of the achievement test, the coefficient of difficulty, and paragraph recognition coefficient. The results of the research showed the superiority of the students who studied the strategy of gradual activities over the students who studied the traditional method at the level of significance(0.05).
\end{abstract}

Keywords: Graduated Activities Strategy, Future Thinking, Second Intermediate Grade, Science Subject . 


\section{الفصل الاول}

problem of the research : 1

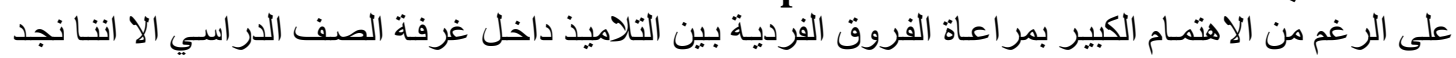

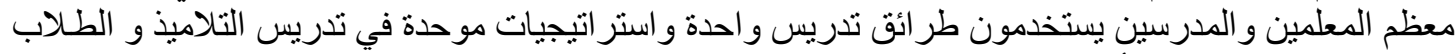

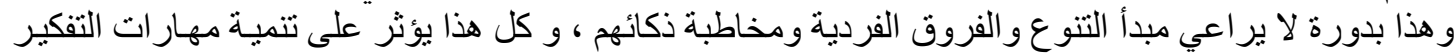

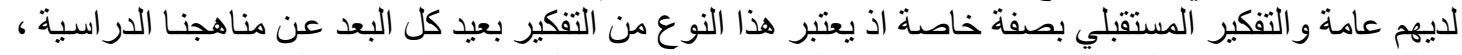

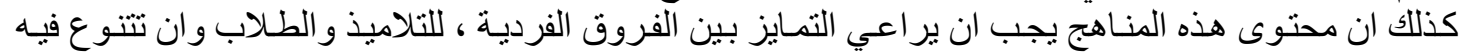

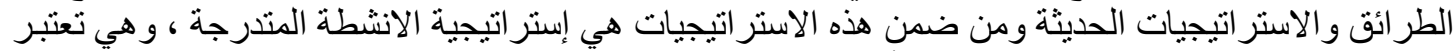

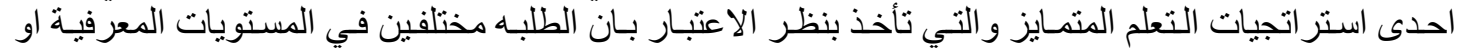

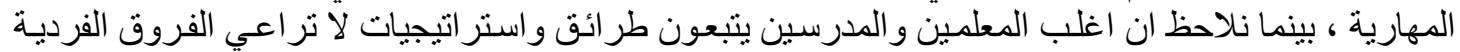

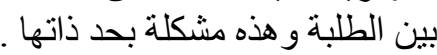

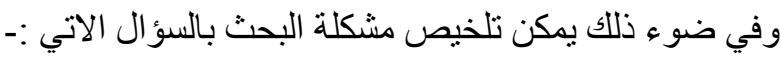
ماهو اثر استخدام إستر اتيجية الانشطة المتدرجة في التفكير المستقبلي لدى طالبات الثاني متوسط في مـادة العلوم

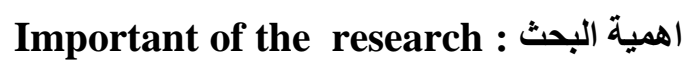

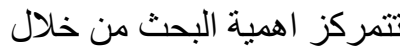

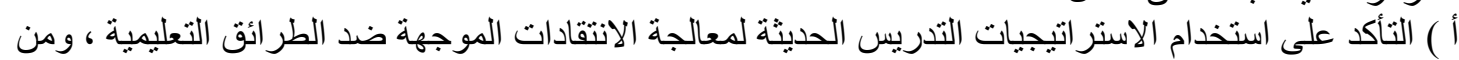

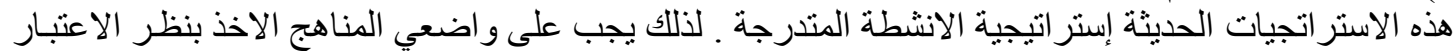

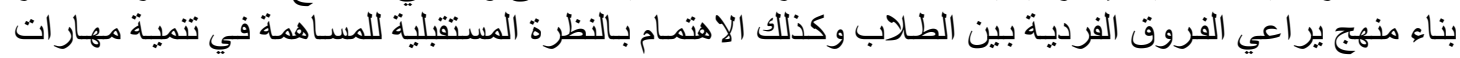

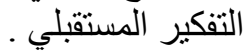
ب) يعتقد الباحثين ( على حد علمهج ) ان هذا البحث هو اول بحث عر اقي يتناول استر اتيجية الانثطة المتدرجة

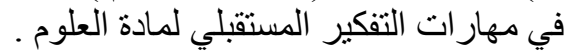

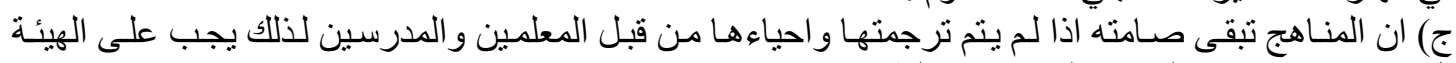

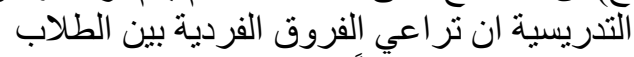

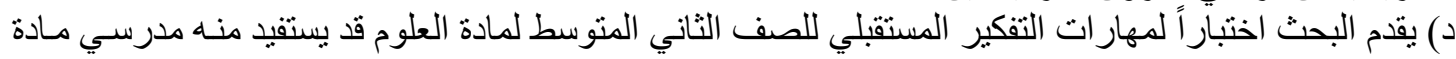
العلوم.

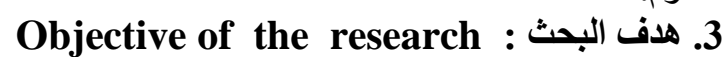
يهدف البحث الحالي الى معرفة اثر استخدام استر اتيجية الانشطة المتدرجة في التفكير المستقبلي لدى طالبات

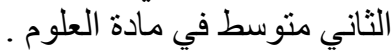
وذللك من خلال آلتحقق من الفرضية الفية الاتية :-

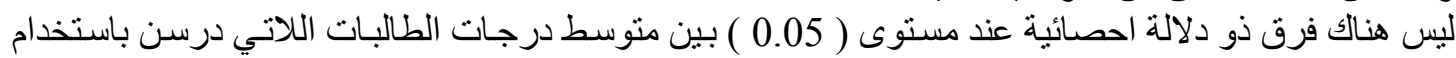

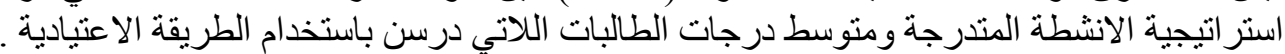

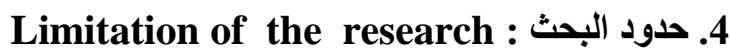
يقتصر البحث الحالي علي :-

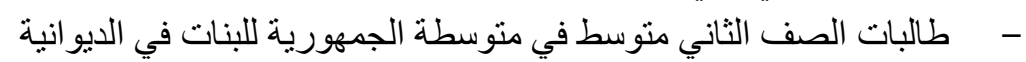

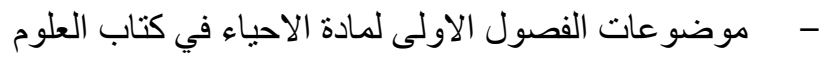

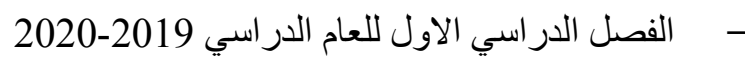

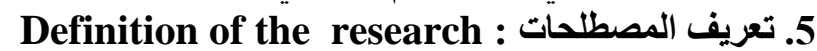

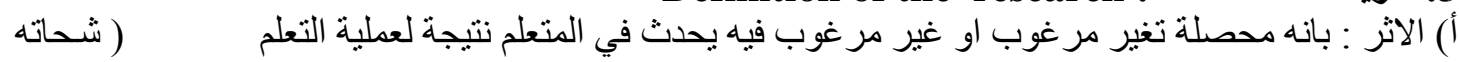

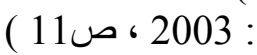
Strategy : بل الإستر اتيجية (11)

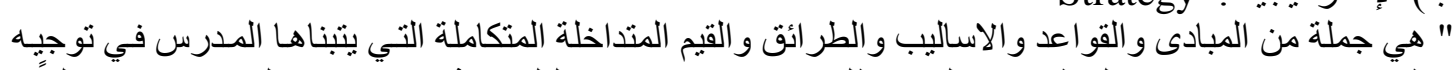

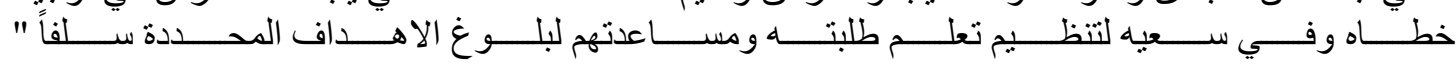

ج) الانتطة المتدرجة : Tirered Activates 
و هي انشطة متدرجه المستوى تقدم للطلاب و التلاميذ في ضو ء قدر اتهم وخصائصـهم وميولهم ، ويتدرج المتعلم

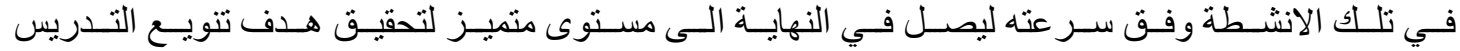

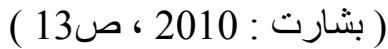

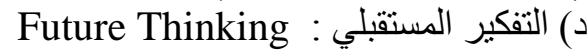

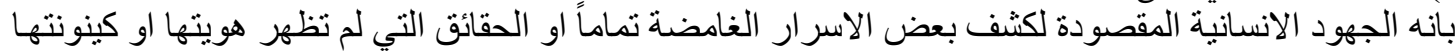

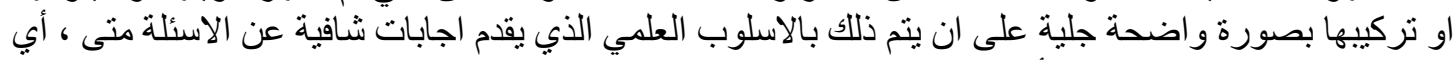

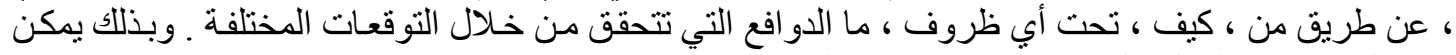

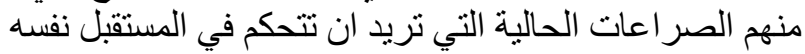

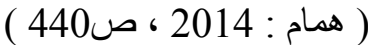

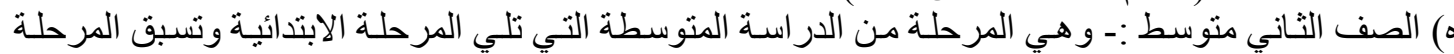

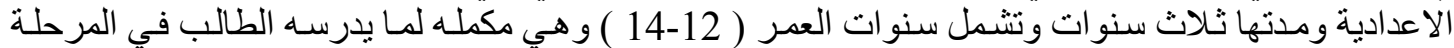
الابتدائية وتزوده معلومات اوسع لما يدرسه الطالب في المرحلة الابتدائية

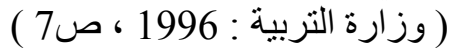

و) مادة العلوم : و هو المنهج و المحتوى المقرر من قبل وزارة النربية للعام الدراسي ( 2019-2020 )

$$
\begin{aligned}
& \text { الفصل الثاني }
\end{aligned}
$$

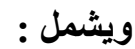

$$
\begin{aligned}
& \text { اولاًا : جو انب نظرية } \\
& \text { ثانياً : الانشطة المتدرجة }
\end{aligned}
$$

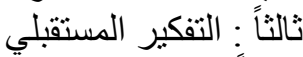

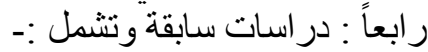

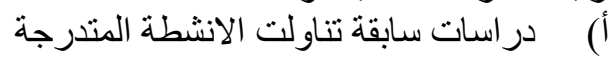

$$
\begin{aligned}
& \text { ب) دراسات سابقة تناولت التفكير المستقبلي لنئي } \\
& \text { اولًا : جوانب نظرية }
\end{aligned}
$$

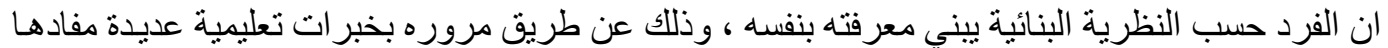

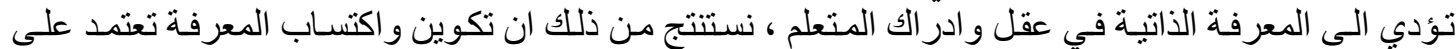

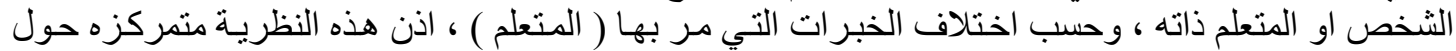

تفاعل المتعلم وتعتبر النظريـة البنائية هي الأسـاس النظري لمعظم الاستر اتيجيات الحديثة للتندريس و التي تعتمد على تفريد

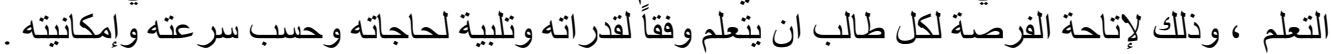

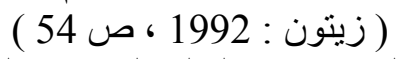

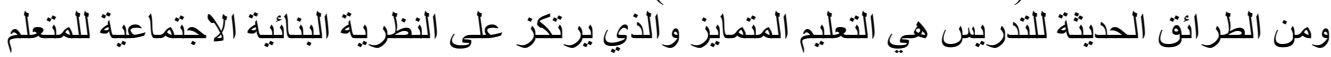

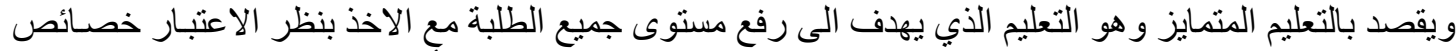

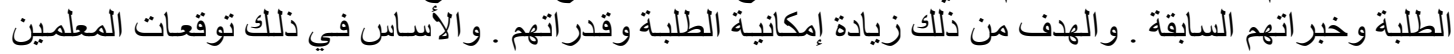

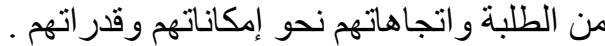

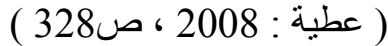

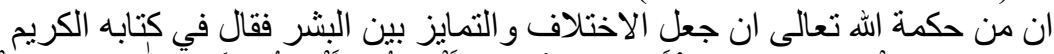

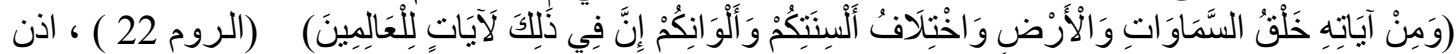

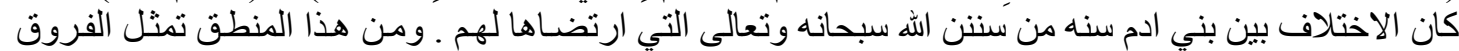

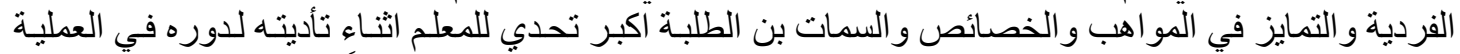

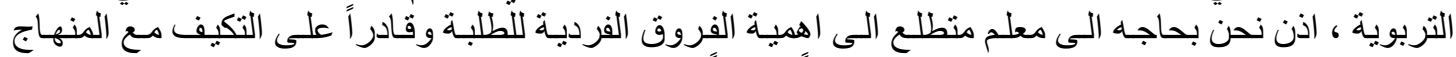

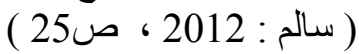

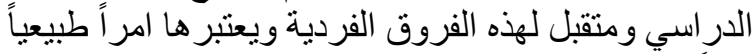

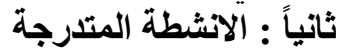

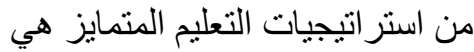
1. إستر اتيجية الانشطة المتدرجة التئي 
العدد (16) أكتوبر 2020

ISSN: 2415 - 4822
Volume (16) October 2020

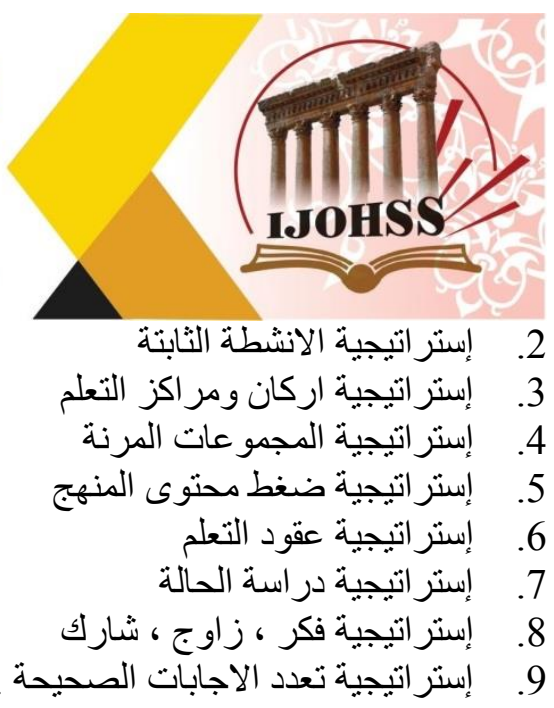

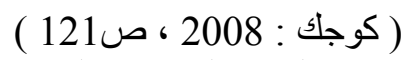

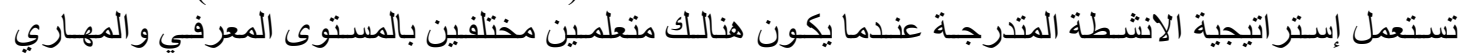

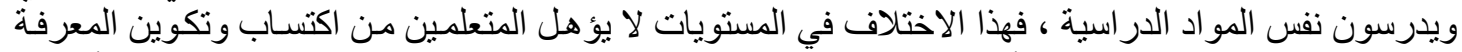

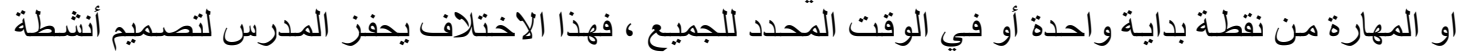

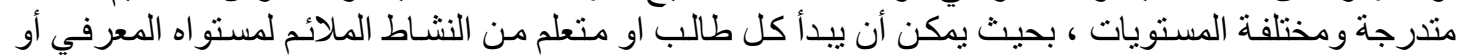

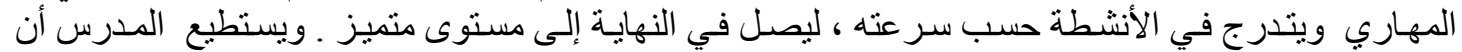

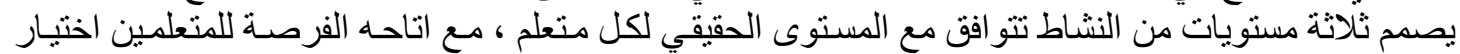

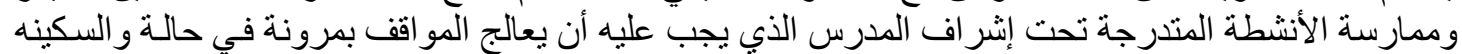

، (داوود، 2006 اتجاه المتعلم في نشاط أعلى أو أقل من مستو اهن الحقيقي.

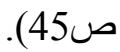

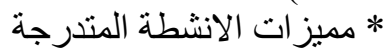

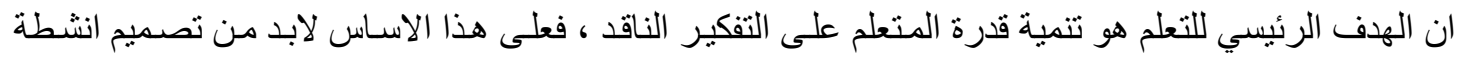

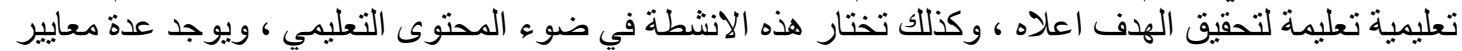

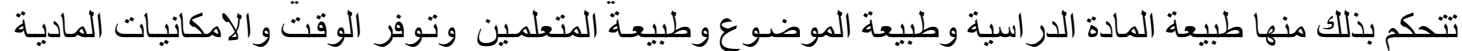

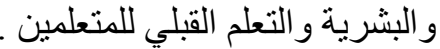

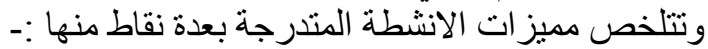

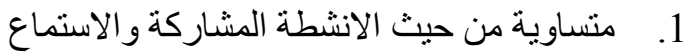

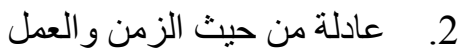

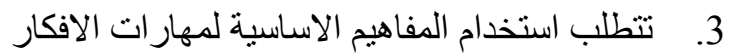

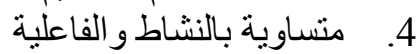
( الشمري : 2011 ، ص125 ) 5.

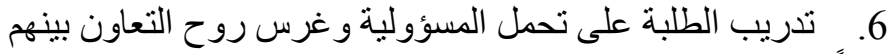

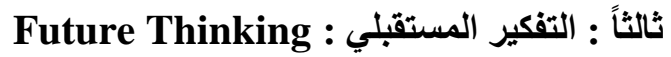
مفهوم التفكير المستقبلي

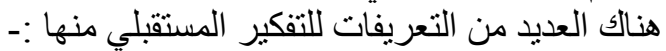

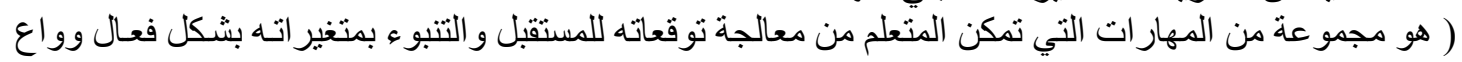

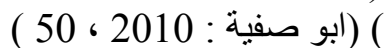
و عرفة عماد حسين ابر اهيم بانه ( عملية عقلية تهدف الى ادر الك المشكلات المستقبلية وصياغة فرضيات جداتيدة

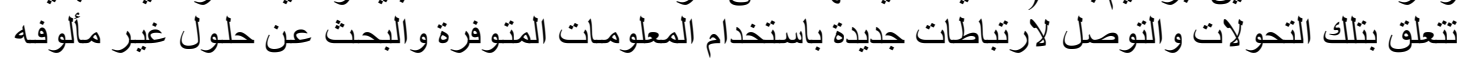

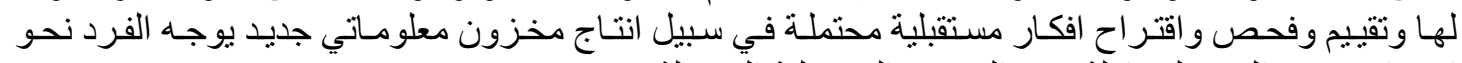

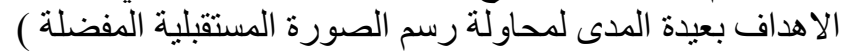

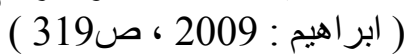

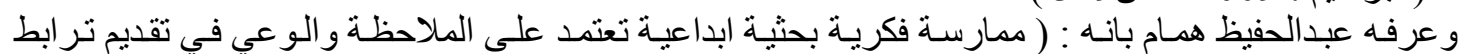

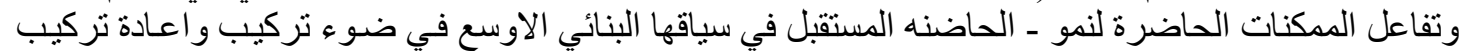

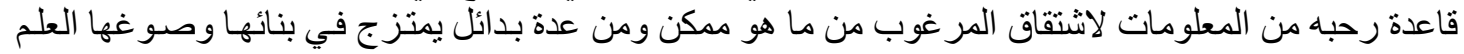

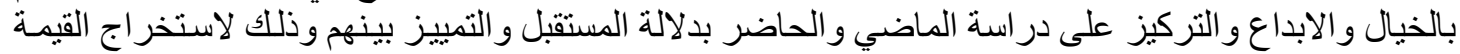
( 440 ، 2014: همام (ل) التربوية لاستشراف المستقبل ) . 


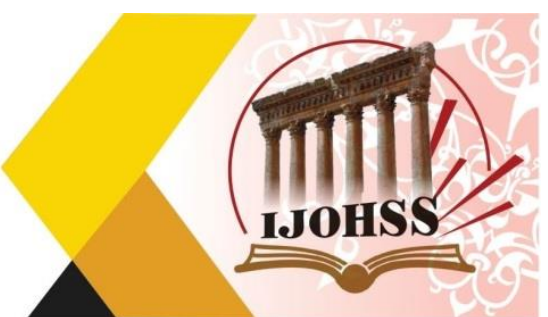

ويعرفه الباحثين :- بانه ناشط عقلي مركب يعتمد على الفهم و التحليل و التركيب لخبرات الطالب اتجـاه المشكلات

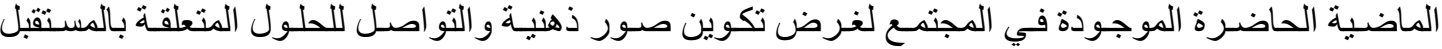

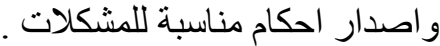

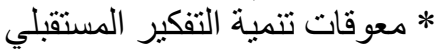

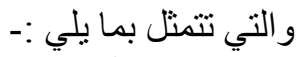

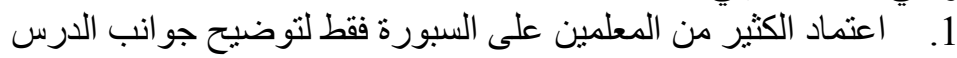

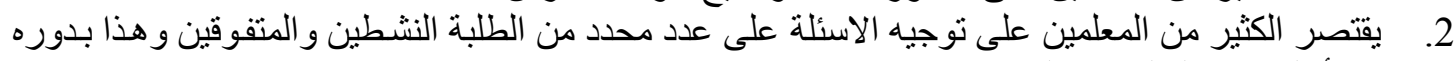

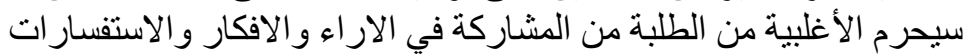

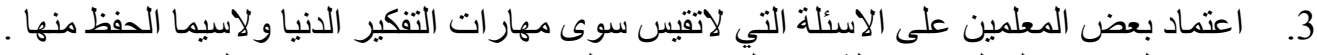
4. عدم تقبل بعض المعلمين لاسئلة او معلومات او معلومات تخرج الألئ عن موضوع الدرس وهذا سيحدد التفكير لأى الطلبة . 5. يعتقد بعض المعلمين بـان المعلم هو صـاحب الكلمـة الاولى و الاخيره داخل الصف وان الكتاب المدرسي

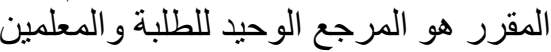
6. مكافأة الطلبة الذين يتصفون بالطاعة و الهدوء من قبل بعض المعلمين و هذا بدوره يسهم في تنشئة جيل يتسم

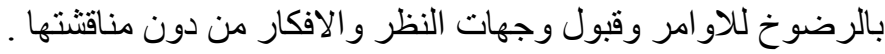

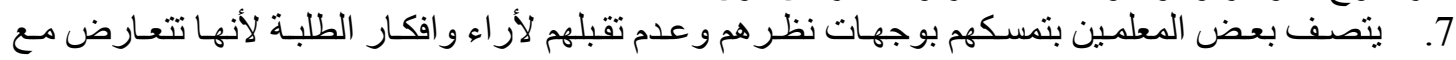

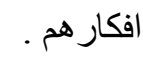

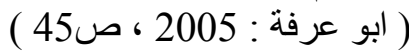

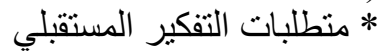
1. على الطالب ان يمنلك "القدرة على وضع اهداف بعيده المدى و التخطيط حسب اولويات المستقبل

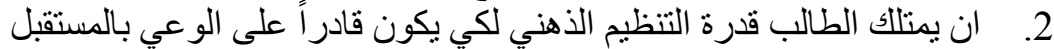

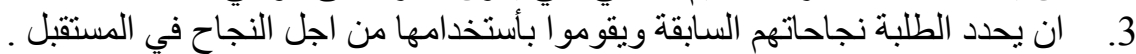
4. قدرة الطلبة على استقر اء التحديات التي قد تبرز في المستقبل وكيفية التغلب عليها في حال حدوثها

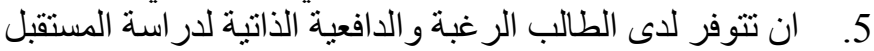

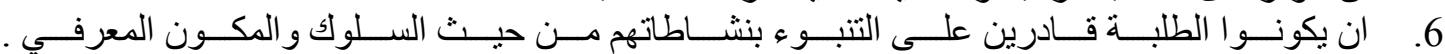

(Hible , 2006 , 25 )

ارتباط التفكير المستقبلي المستبلي بعدة مهار ات كفيلة و التي يمكن ان يمارسها الفرد ويستخدمها عن قصد في معالجة

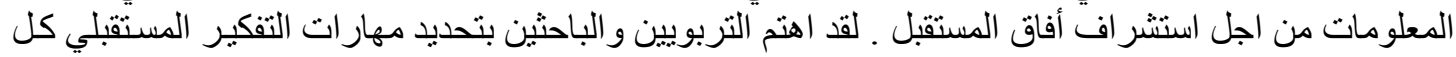
حسب وجهة نظره وحسب توجيهاته التربويه ومن ذلك الك مايلي :حدد رمضان فوزي المنتصر مهار ات التفكير المستقبلي فيما يلي :1 2. 2

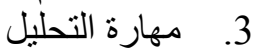

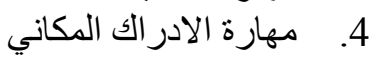

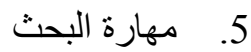

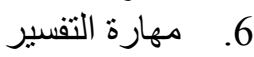
( جاد الله : 2013 ، ص42 )

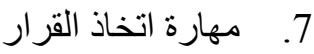

ويشير عماد حسين حافظ بأن مهار ات التفكير المستقبلي نتمثل في :1 2. مهارة حل المشكلات المستقبلية

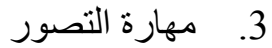

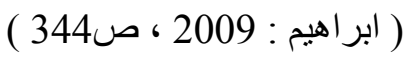

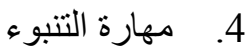
حاول الباحثون اخذ مهار ات مشتركة للاعتماد عليها في هذا البحث و هي كالاتي :- 
المجلة اللدولية للعلوم الإنسانية والإمتاعية

International Journal of Humanities and Social Sciences

website:www.ijohss.com

Email:editor@ijohss.com

العدد (16) أكتوبر 2020

Volume (16) October 2020

1. مهارة التنبوء :- وتعني قدرة الطالب على ايجاد صورة مستقبلية محتملة للمشكلات المعاصرة وبناء اتجاهات

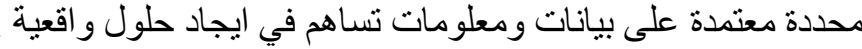

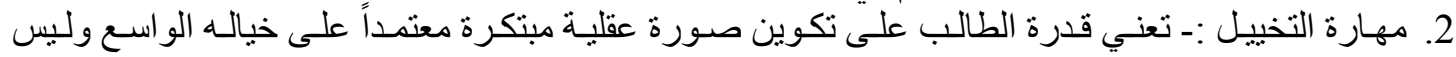

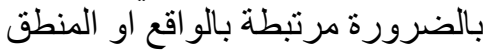

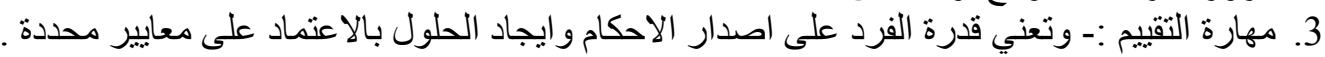

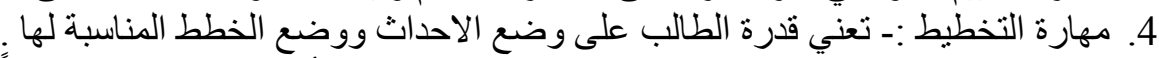

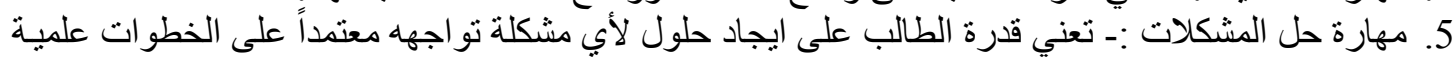
منظمة مبارة 6. مهارة اتخاذ القرار :- وتعني قدرة الطالب على التعامل مـع أي مشكلة واصدار الاحكام و القرار ات المناسبة لحلها. ( متولي : 2010 ، صلو64 )

رابعاً :- دراسات سابقة وتثشمل: وانعا:

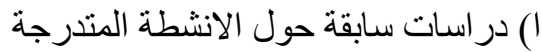

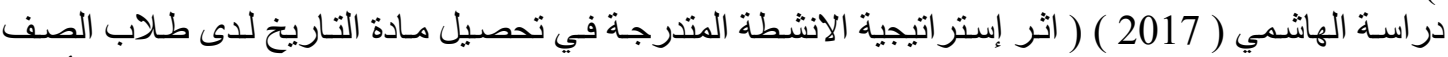

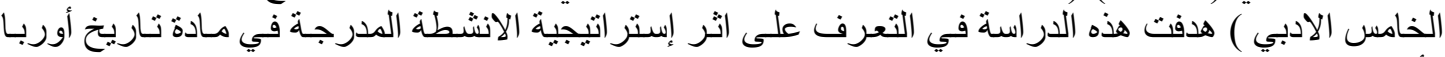

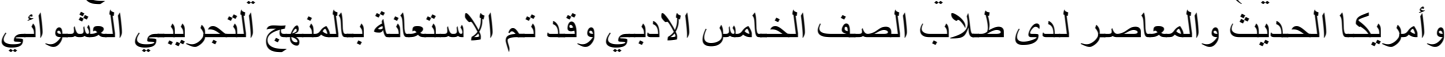

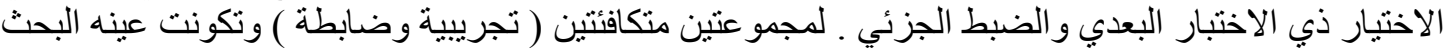

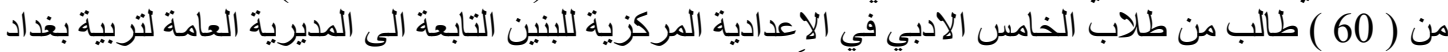

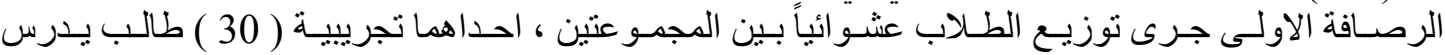

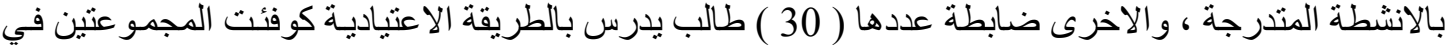

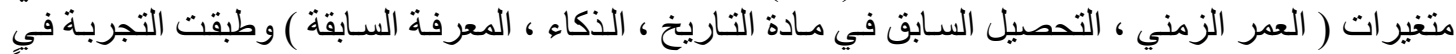

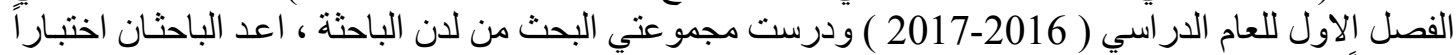

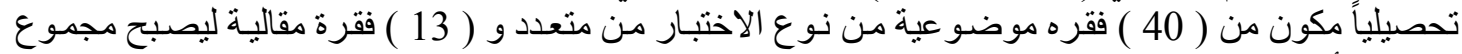

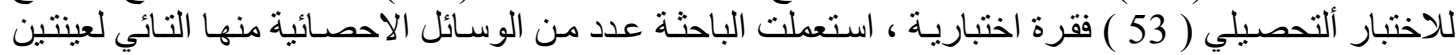

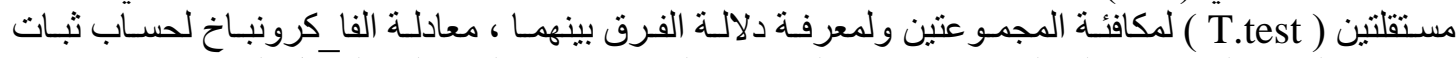

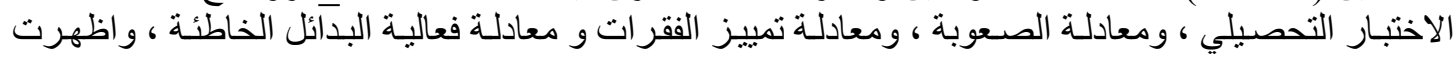

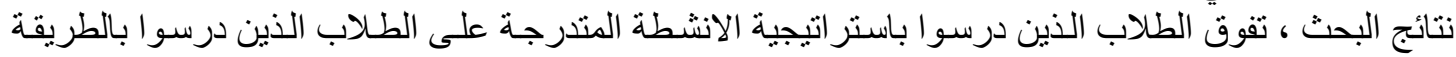

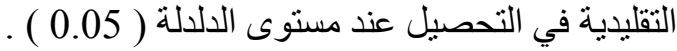
ب) در اسات سابقة حول التفكير المستقبلي منئي

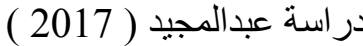

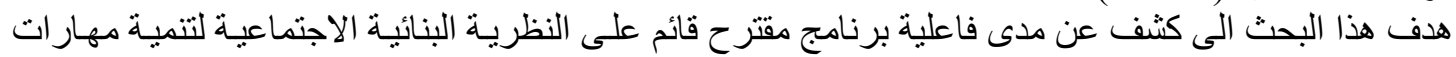

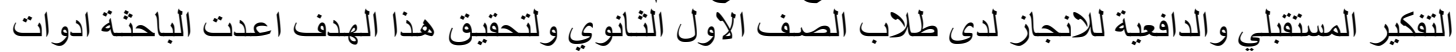

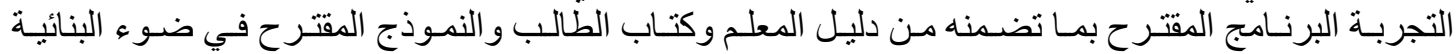
الاجتماعية وقائمة مهار ات التفكير المستقبلي وقائمة ابعساد الدافعية للانجاز واستخدمت الباحثة اداتا قياس اختبـار

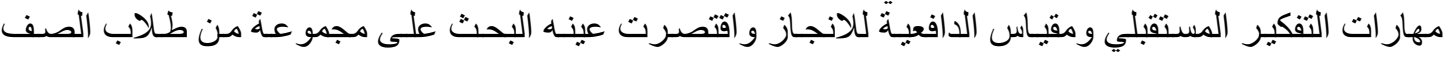

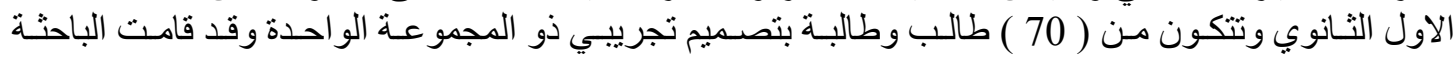

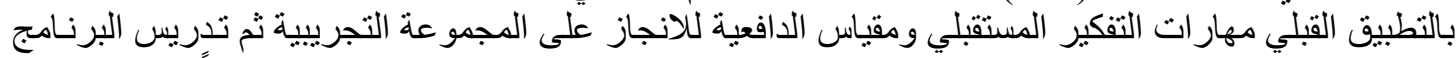

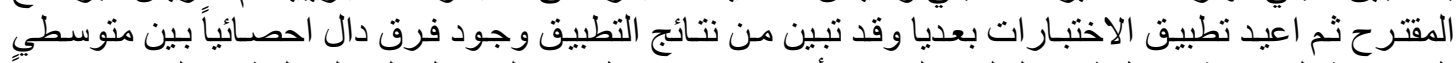

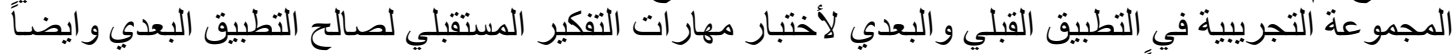

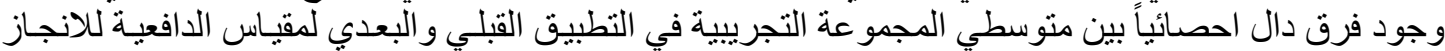
لصالح التطبيق البعدي . في دال 
International Journal of Humanities and Social Sciences

website:www.ijohss.com

Email:editor@ijohss.com

العدد (16) أكتوبر 2020

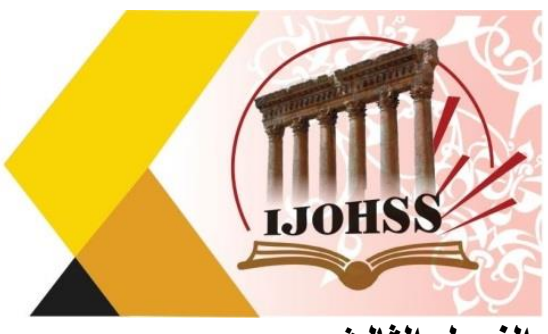

ISSN: $2415-4822$

Volume (16) October 2020

\section{القصل الثالث}

منهجية البحث و إجر اعاته الته الته

يتضمن هذا الفصل كل الاجر اءات التي تسعى الباحثة القيام بها من حيث اختئار التصميم التجريبي ، واختيار

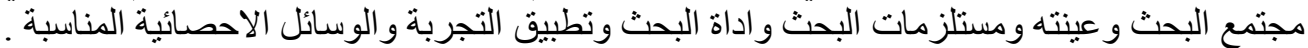

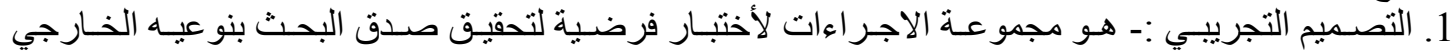

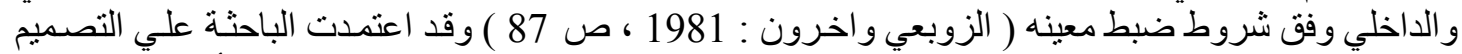

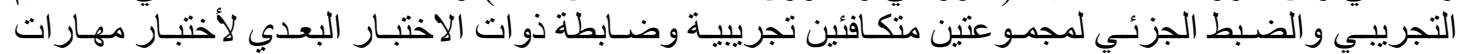

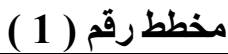

التفكير المستقبلي وكما موضح

\begin{tabular}{|c|c|c|c|c|}
\hline (التتبار بعدير التابع) & المتغير المستقل & التكافؤ & المجمو عة & ت \\
\hline \multirow{2}{*}{ المستقبلـي ات التفكيـــر } & الطريقة التقليدية & \multirow{2}{*}{ العمر بالاشهر التصـيلي السـابق في مـادة العلـوم } & الضـابطة & 1 \\
\hline & $\begin{aligned} \text { إستدر اتيجية الانشطة } & \\
& \end{aligned}$ & & التجريبية & 2 \\
\hline
\end{tabular}

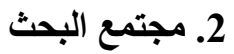

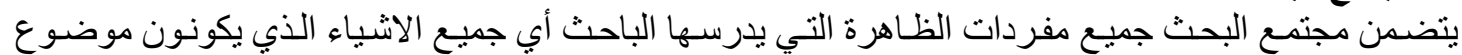

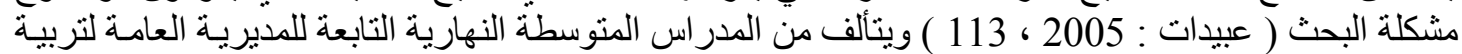

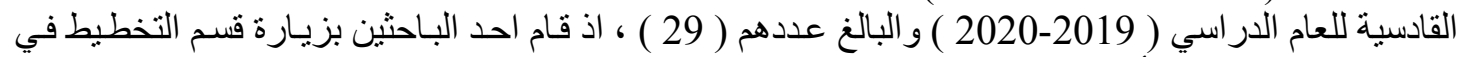

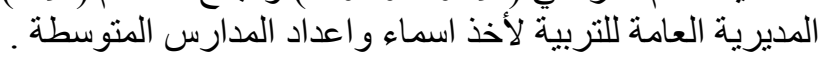

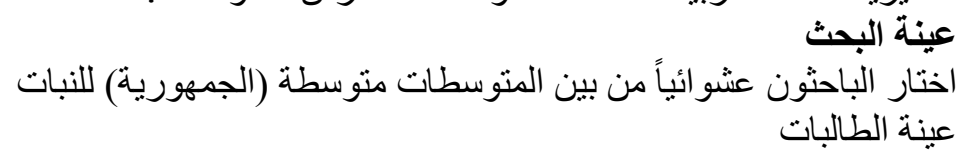

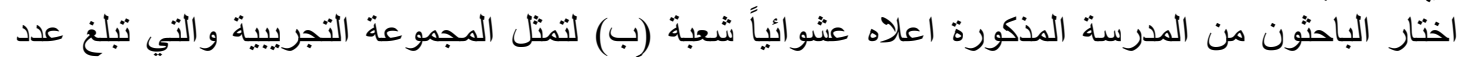

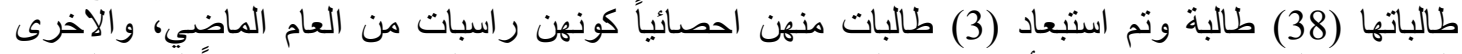

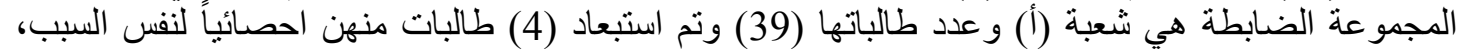

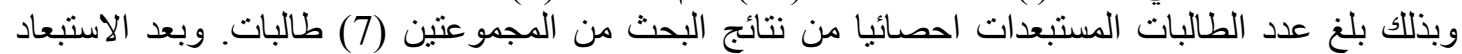
اصبح عدد طالبات عينة البحث (70) طالبة البة بوات اقع (35) طالبة لكل مجمو عنة.

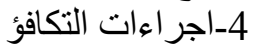
لغرض تحقيق السلامة الداخلية للتصميم تم اجر اء التكافؤ بين المجمو عتين التجريبية و الضابطة في عدد من

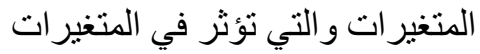
التابعة عن طريق تفاعلهاً مع المتغير المستقل وكما موضح في الجدول (1)

\begin{tabular}{|c|c|c|c|c|c|c|c|}
\hline الدلالة الاحصائية (0.05) ودرجة حرية & \multicolumn{2}{|c|}{ القيمة ت } & \multicolumn{2}{|c|}{ الضابطة } & \multicolumn{2}{|c|}{ التجريبية } & المجمو عة \\
\hline & الجة & المحسوبة & 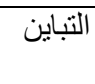 & الحسابي & 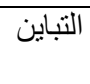 & الحسابي & \\
\hline 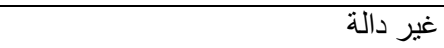 & \multirow{3}{*}{1.99} & 1.10 & 25.43 & 151.26 & 45.26 & 152.83 & العمر الزمني بالاشهر \\
\hline 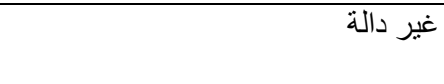 & & 0.96 & 18.29 & 70.67 & 15.94 & 74.57 & السابق في مادة العلّوم التيل \\
\hline غير دالة & & 0.51 & 12.35 & 13.23 & 26.77 & 13.77 & الذكاء \\
\hline
\end{tabular}


المجلة الدولية اللملور الأسسانية والإمتماعية

International Journal of Humanities and Social Sciences

website:www.ijohss.com

Email:editor@ijohss.com

أكتوبر 2020

العدد (16)

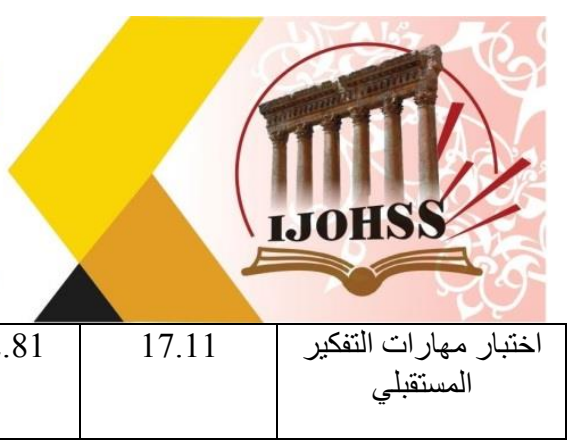

Volume (16) October 2020

ISSN: 2415 - 4822

\begin{tabular}{|l|l|l}
\hline 42.46 & 18.11 & 22.81 \\
\hline
\end{tabular}

\section{جدول (1)}

4-السلامة الخارجية للتصميم التجريبي تم معالجة العو امل المؤثرة في السلامة الخدانة الخارجية وكالآتي:

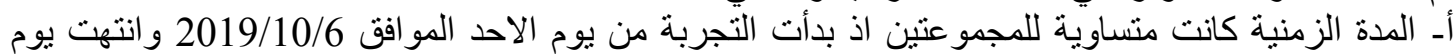

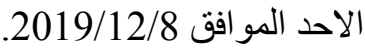

بـ الادوات المستخدمة: استخدم الباحثون نفس الاداة مع مجموعتي البحث وهي اختبار مهارات التفكير

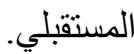
ج- البيئة الصفية: تم تدريس مجمو عتي البحث في نفس المكان (مختبر العلوم) وبحسب الجدول.

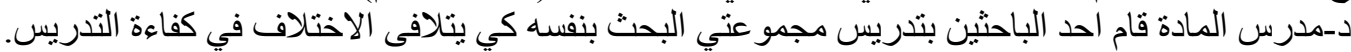

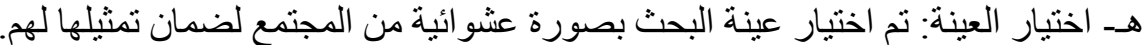

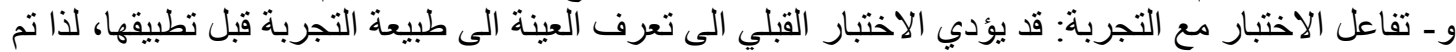

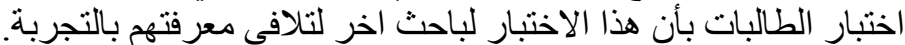

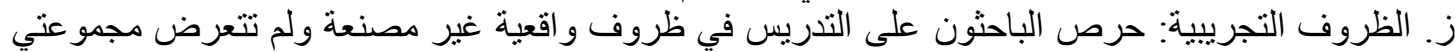

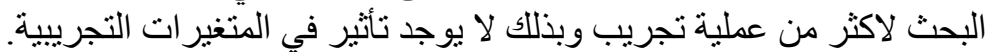
5-مستلزمات البحث من البر

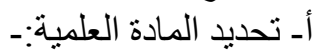

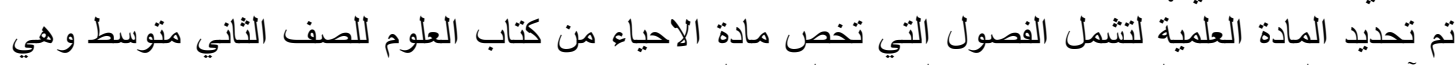
كالآتي:- (التصنيف و التنوع، خصائص الكئن الكائنات الحية، البيئة ومواردها) بـ صياغة الاهداف السلوكية

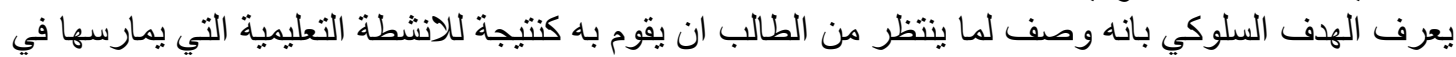

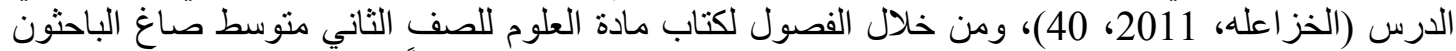

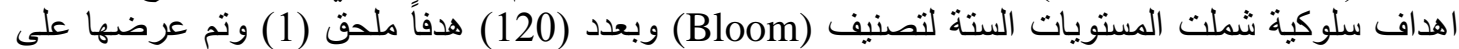

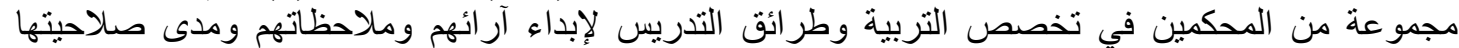

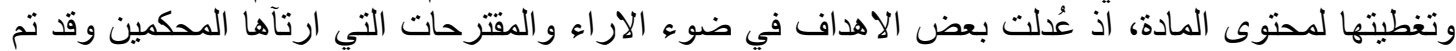

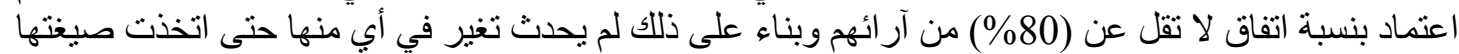
النهائية.

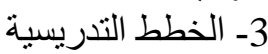

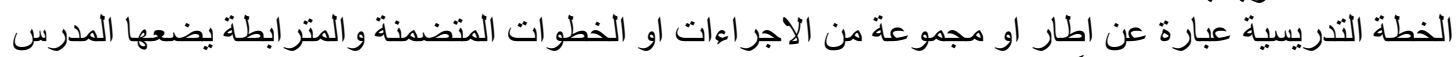

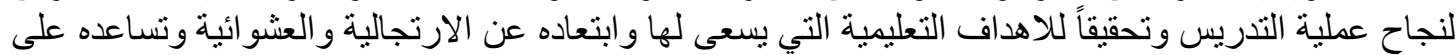

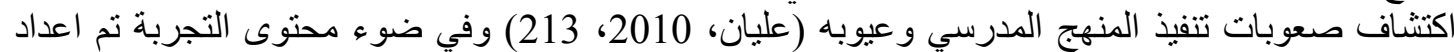

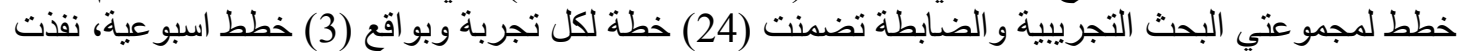

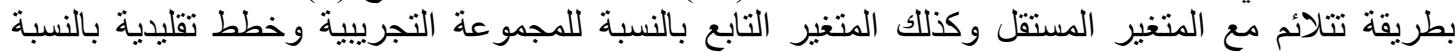
للمجموعة الضابطة وتم عرض جمئم الفيع الخطط على مجموعة من المحكمين و الخبراء في مجال التربية وطر ائق

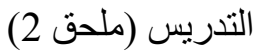

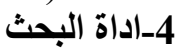

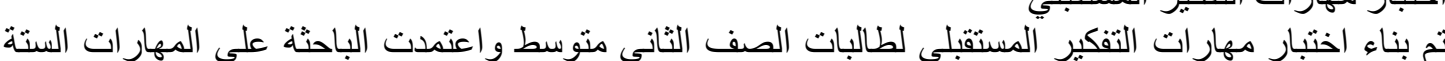

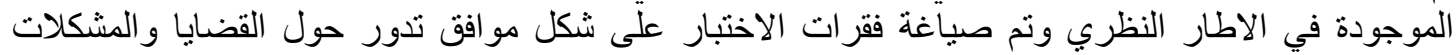

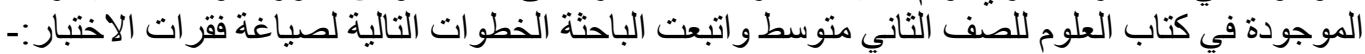

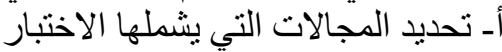

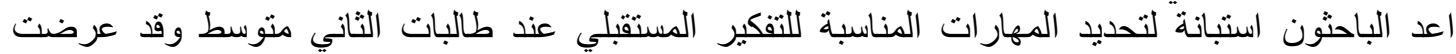

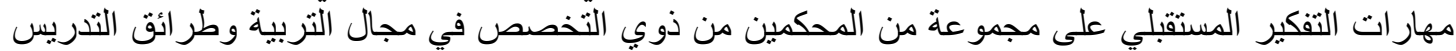

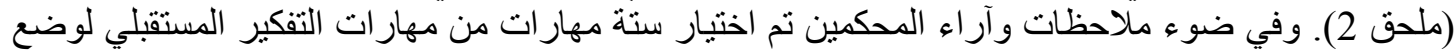




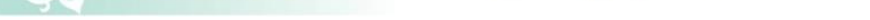

\section{Volume (16) October 2020}

(عبيدان وسهيلة: 2005، 113).

ب-بناء فقر ات الاختبار

بعد اطلاع الباحثين على اختبار ات مهار ات التفكير المستقبلي في مجالات عديدة، وبالاعتماد على الخلفية النظرية

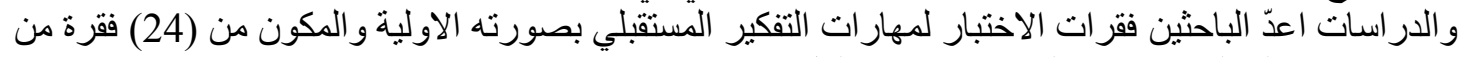

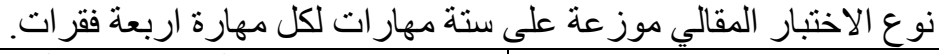

\begin{tabular}{|c|c|c|}
\hline عدد الاسئلة & ارقام مفردات اسئلة الاختبار و التي & مهار ات التفكير المستقبلي \\
\hline 4 & $20 ، 14 ، 8 \cdot 2$ & التخيل \\
\hline 4 & $19 ، 13 ، 7 ، 1$ & اتخاذ القرار \\
\hline 4 & $22 \cdot 16 \cdot 10 \cdot 4$ & التنبؤ \\
\hline 4 & $21 \cdot 18 \cdot 12 \cdot 3$ & التقبيم \\
\hline 4 & $23 \cdot 15 \cdot 9 \cdot 6$ & حل المشكلات \\
\hline 4 & $24 \cdot 17 \cdot 11 \cdot 5$ & التخطبط \\
\hline
\end{tabular}

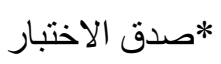

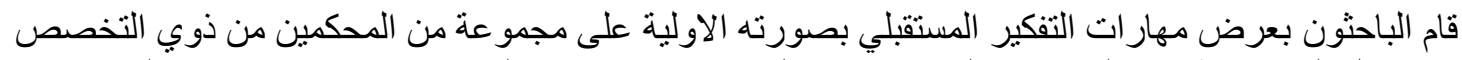

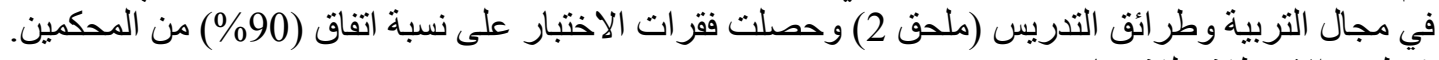

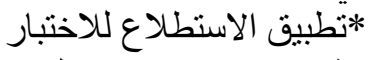
تطبيق اختبار مهارات التفكير المستقبلي على عينتين الإنين استطلاعيتين وكما يلي:-

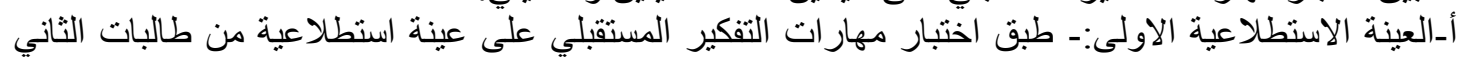

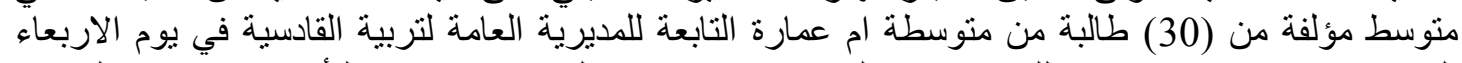

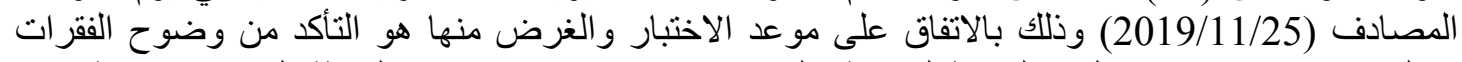

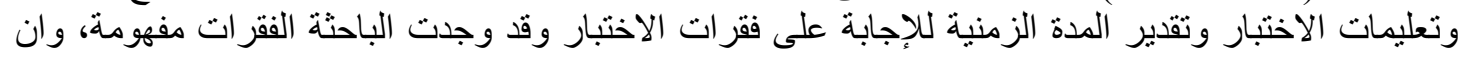

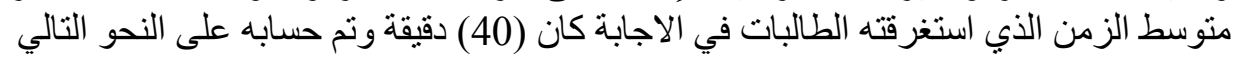

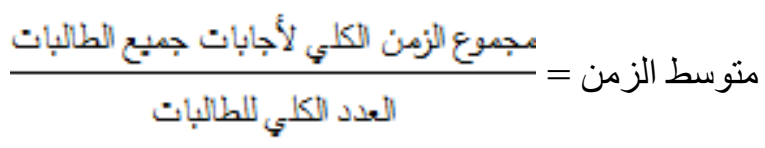

$$
\begin{aligned}
& 1187 \\
& \text { منتوسط الزمن = } 30 \text { = } 40 \text { دقيقة }
\end{aligned}
$$

(النجار: 2010، (30)

بـ العينة الاسنطلاعية الثانية:

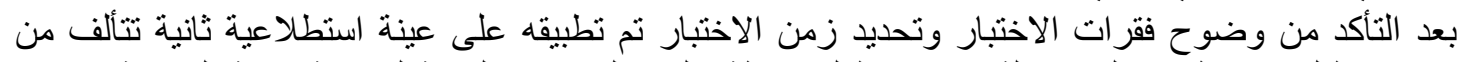

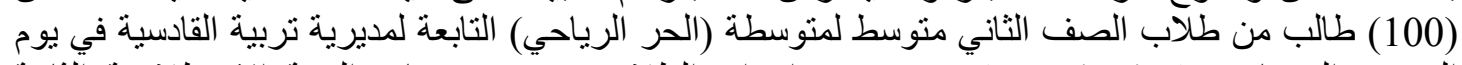

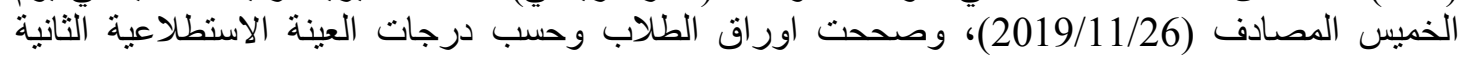

بـ التحليل الاحصائي لفقر ات الاختبار

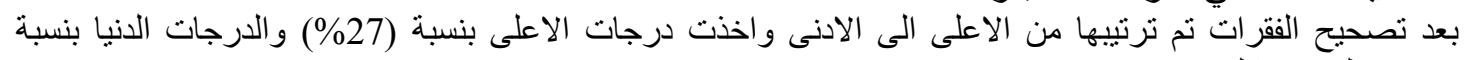

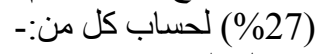

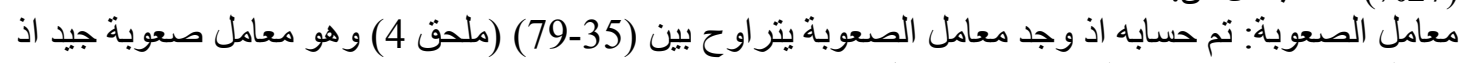

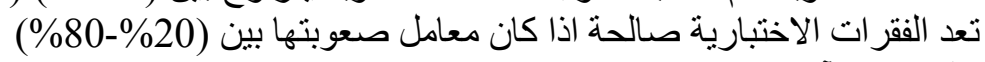

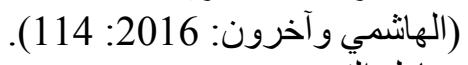

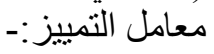




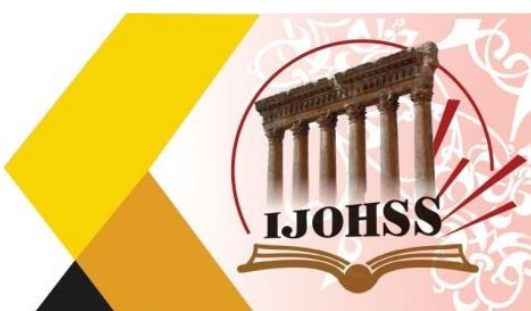

ISSN: $2415-4822$

Volume (16) October 2020

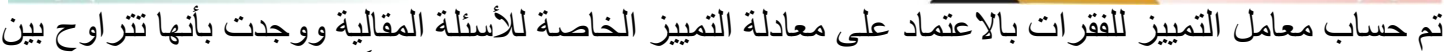

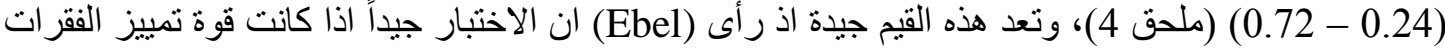

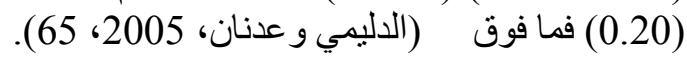

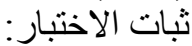

تحقق الباحثين من ثبات الاختبار بطريقة الفاكرونباخ، ثم ايجاد ثبات الفقرات بطريقة التجانس الداخلي و الاعتماد

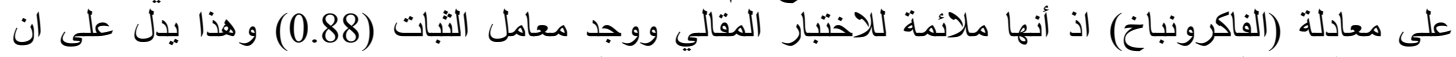

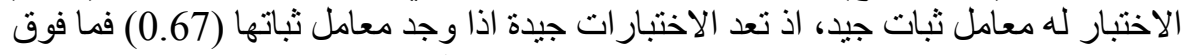

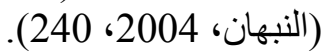

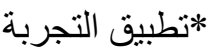
طبقت التجربة يوم الاحد الموافق 2019/10/6، وانتهت يوم الاحد الموافق 2019/12/8 وتم تطبيق اختبار

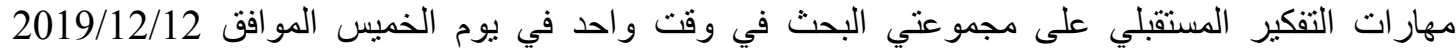
و اشرفت احد الباحثة على عملية تطبيق الاختبار.

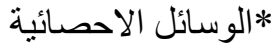

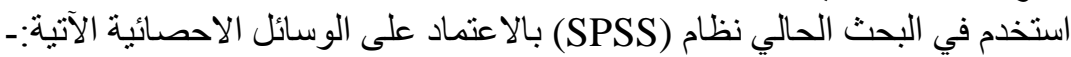

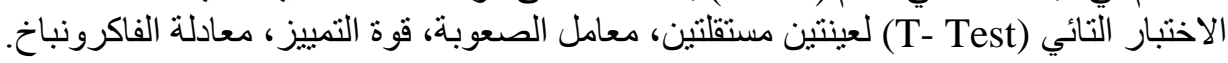

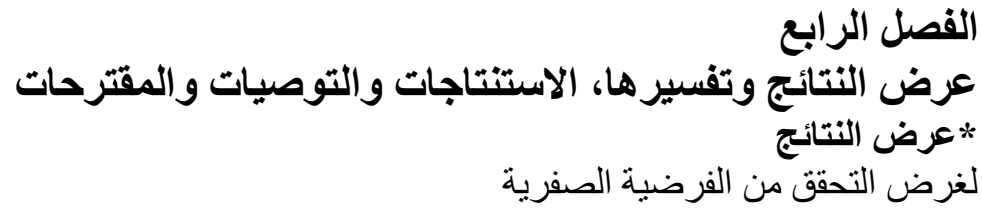

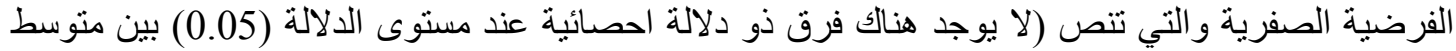

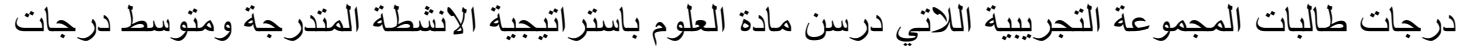

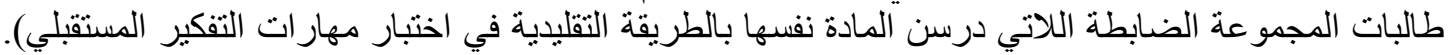

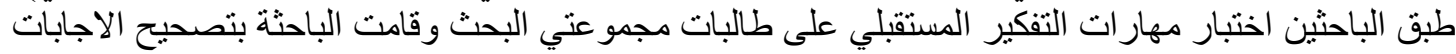

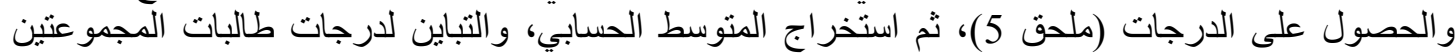

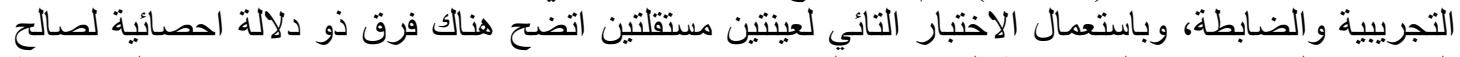

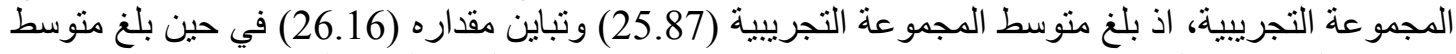

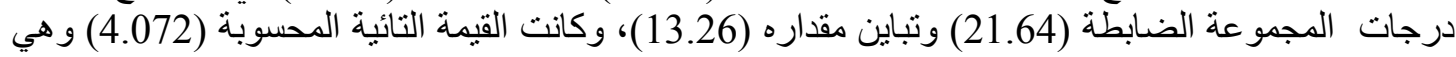
اكبر من الجدولية (1.99) وبدرجة حرية (68) و الجدول (3) يوضن (13) وضنح ذلك.

\begin{tabular}{|c|c|c|c|c|c|c|c|}
\hline \multirow{2}{*}{ الدلالة عستوى } & \multicolumn{2}{|c|}{ القيمة التائية } & \multirow{2}{*}{ الحرجة } & \multirow[b]{2}{*}{ التباين } & \multirow{2}{*}{ الحسابي } & \multirow{2}{*}{ عدد افر اد } & \multirow[b]{2}{*}{ المجمو عة } \\
\hline & الجدولية & المحسوبة & & & & & \\
\hline دالة & \multirow{2}{*}{1.99} & \multirow{2}{*}{4.072} & \multirow{2}{*}{68} & 26.16 & 25.87 & 35 & التجريبية \\
\hline احصائية & & & & 13.26 & 21.64 & 35 & الضابطة \\
\hline
\end{tabular}

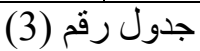

و هذا يدل على تفوق طالبات المجموعة التجريبية التي درست مادة العلوم بطريقة استراتيجية الانشطة المتدرجة على طالبات المجمو عة الضابطة و التي درست وفق التر الطريقة التقليدية.

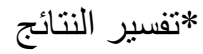

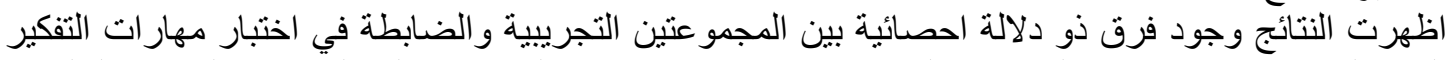

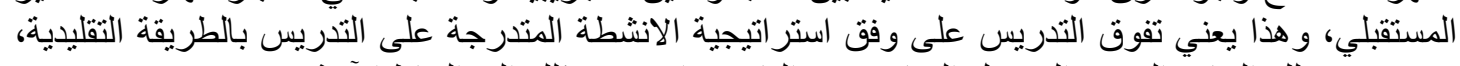

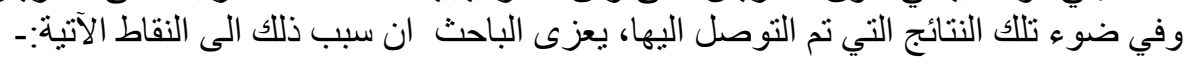




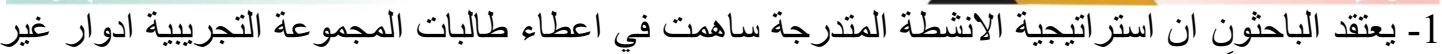

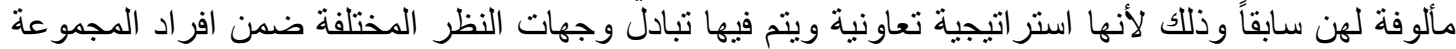

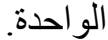
2- تر اعي استراتيجية الانثطة المتدرجة الفروق الفردية، بل تعتمد عليها في تصنيف الطلاب وتوزيعهم على

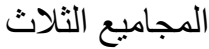
3- ان استعمال استر اتيجية الانشطة المتدرجة في التدريس تجعل من الطلاب ذو فاعلية ومشاركة اوسع واكبر

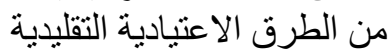

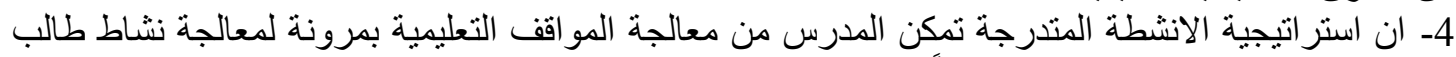
اعلى او اقل من مستو اه الحقيقي، فهي اذاً نر اعي القدر العند ات العقلية للطلبة.

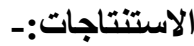
1-نوفر الانشطة المندرجة تنتافساً ايجابياً بين طالبات المجمو عات فهي تزيد من التفاعل مما يؤدي الى نوفر موقفاً

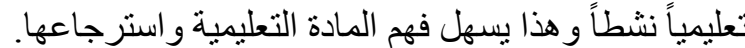

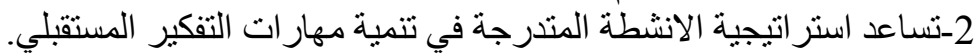

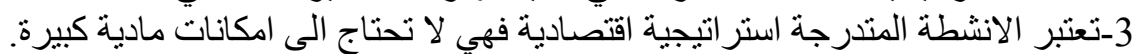
4-تمكن استر اتيجية الانشطة المتدرجة المدرس من تخطيط وتعميم الدرس. 2-تطبيق استر اتيجية الانشطة المتدرجة على مو اد در اسية ومر أحل در اسية اخرى.

التوصيات:1-التأكيد على المديريات العامة للتربية بإقامة الدورات التدرييية للمدرسين باستخدام استراتيجية الانشطة المتدرجة في العملية التدريسية التئية 2-ضرورة تضمين البرنامج الجامعي لطلاب كلية التربية و التربية الاساسية للاستر اتيجيات الحديثة ومن ضمنها استر اتيجية الانشطة المتدرجة. 3-على و اضعي المناهج مر اعاة تقديم محتوى در اسي ينلاءم و استر اتيجية الانشطة المتدرجة.

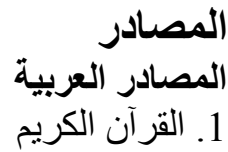

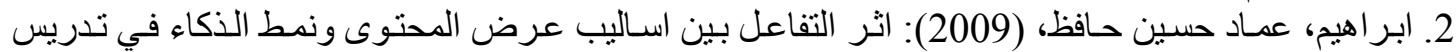

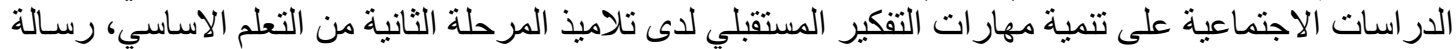

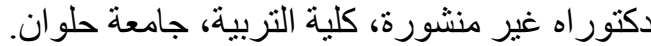

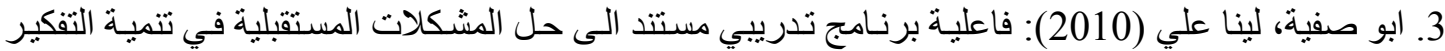
المستقبلي لاى عينة من طالبات الصف العانشر في الزرقاء ، أطروحة دكتور اه غير منشورة ، الجامعة الاردنية ،

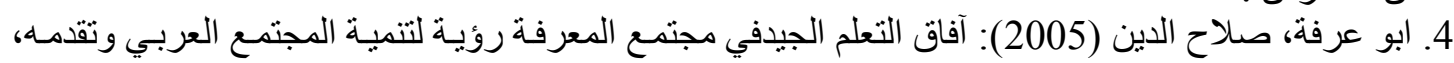

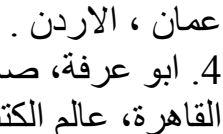

5. بشارت، محمد سليم (2010): تنويع التدريس، دورة تدريبية، نجر ان، المملكة العربية السعودية.

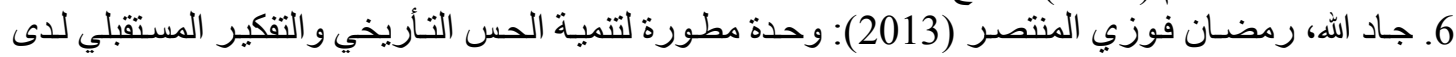

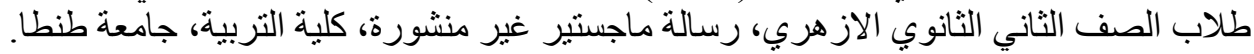

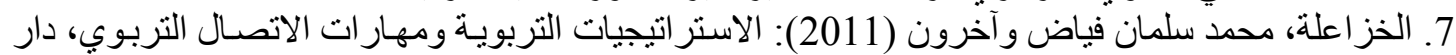

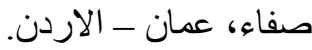
8. خضر ، محسن (2008): مستقبل التعليم بين الكارثة و الامل، ط1، الدار المصرية، جامعة عين شمس. 


\section{المجلة اللدولية للملوم الآنسانية والإمتاعية}

International Journal of Humanities and Social Sciences

website:www.ijohss.com

Email:editor@ijohss.com

العدد (16) أكتوبر 2020

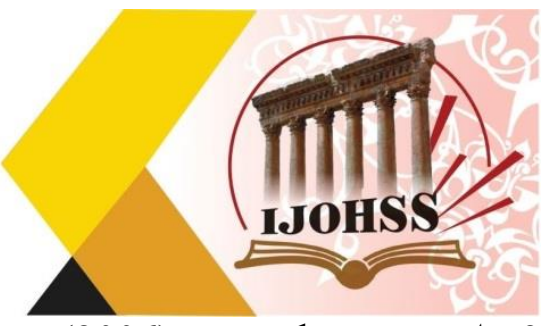

ISSN: 2415 - 4822

Volume (16) October 2020

9. داوود، وديـع مكسيموس (2006): موديـول اسـتر اتيجية التدريس والانشـطة، كليـة التربيـة، جامعـة اسـيوط،

10. الدليمي، احسان عليوي و عدنان محمود المهداوي (2005)، القياس و التقويم، ط2 مكتبـة احمد الدباغ، بغداد

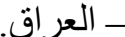

11. الزوبعي، عبد الجليل ابر اهيم وآخرون (1981): الاختبار ات و المقاييس النفسية، دار الكتب للطباعة والنشر، جامعة الموصل.

12. زيتون، حسن وكمال زيتون، (1992): البنائية من منظور استرلوجي وتربوي، ط1، الاسكندرية.

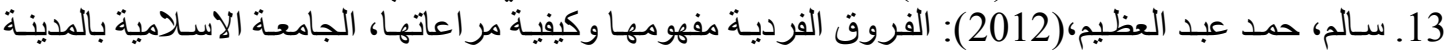
المنورة، التوجيه التربوي.

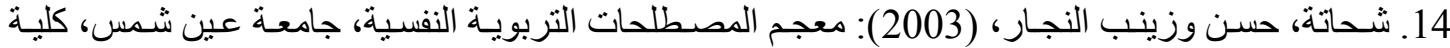
التربية، الدار المصرية، القاهرة حنئة

15. الشــري، ماثـي بـن محمد (2011): اسـتر اتيجية في التعليم النشط، ط1، مطبعـة صـائل، المملكـة العربيـة السعودية.

طالبات الصف العاشر في الزرقاء، اطروحة دكتور اه غير منشورة، الجامعة الاردنية، عمان، الاردن.

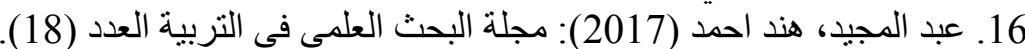

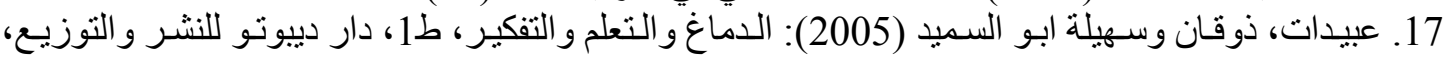
عمان - مان - الاردن.

18. عطية، محسن علي (2008): الاستر اتيجيات الحديثة في التدريس الفعال، دار صفاء، عمان.

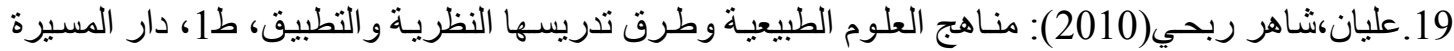

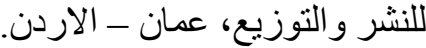

20. كوجك، كوثر حسين و آخرون (2008): نتونة (لتونيع التدريس، محرر عالم الكتب.

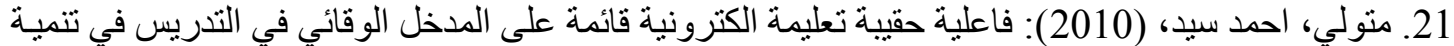

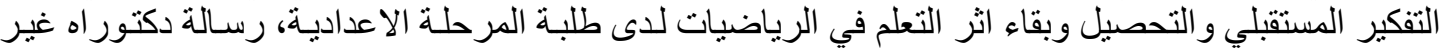

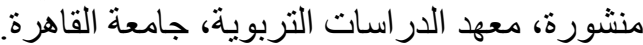

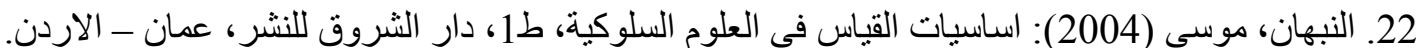

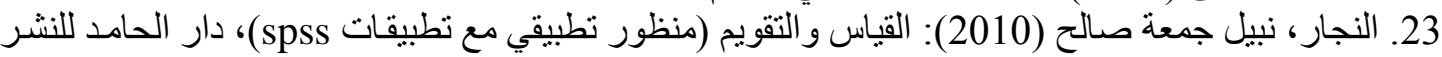
و التوزيع، عمان - الاردن.

24. الهاثمي: حيدر ماجد ابر اهيم (2017)، مجلة الفنون والادب و علوم الانسانيات و الاجتماع، العدد (13).

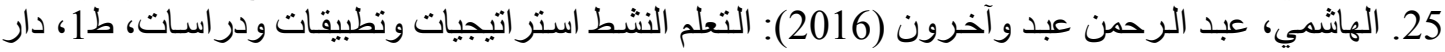

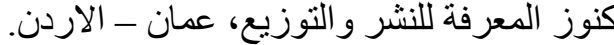
26. همام. عبد الحفيظ: (2014)، المناهج الدر اسية بين الاصـالة و المعاصرة واستشـر اف المستقبل، ط1، القاهرة عالم الكتب 27. وزارة التربية ، (1996): نظام المدارس الثانوية، قسم (2)، مطبعة وزارة التربية، بغداد.

المصادر الاجنبية

1-Hible, (2006): Futur Problem, salving: Taking it beyond the classroom, Retsieved 22/4/2006, http://seenceDirect.com . 